\title{
EL IDEAL DE HUMANIDAD Y LAS HUMANIDADES. Dialogando con Kant, Fichte y Husserl ${ }^{1}$
}

\author{
THE IDEAL OF HUMANITY AND THE HUMANITIES. \\ ReVisiting Kant, Fichte, AND HuSSerL
}

\begin{abstract}
Resumen: El papel de filosofía y humanidades en forjar un "ideal de humanidad" se refiere no sólo a las difíciles relaciones que éstas tradicionalmente han tenido con los poderes mundanos, sino, sobre todo, a su papel protagónico como guías de un ideal de humanidad y valores espirituales en tiempos de crisis. Kant defendió el papel de los ideales racionales de la "facultad de filosofía" a fines del s. XVIII, ante la teología, el derecho y la medicina. La reflexión de Fichte cuando la nación alemana luchaba por su existencia luego de su derrota por los ejércitos napoleónicos a inicios del s. XIX, da un impulso decisivo a los valores del idealismo alemán. Un siglo después, ante la misma nación alemana, nuevamente derrotada en la primera guerra mundial y sin hallar respuestas a su aflicción en las ciencias exactas ni en su cultura determinada por la técnica, Husserl ve en "el ideal de Humanidad de Fichte" la respuesta a aquello que puede darle su ultima satisfacción: la producción teleológica de un mundo humano, en el que pueda realizarse un orden mundial moral, único fin, fundamento y valor absoluto de la humanidad. Hoy nos hallamos en otro momen-to de peligro: no sólo el del positivismo naturalista desplazando desde el s. XIX a la formación humanística. El mayor de los peligros es ahora la alianza de ese naturalismo con el mundo globalizado del presente, bajo el imperio de la estandarización burocrática y corporativa al servicio de la producción desenfrenada de dinero.
\end{abstract}

Palabras clave: Kant. Fichte. Husserl. Idealismo alemán. Humanidades. Valores racionales.

\author{
Rosemary Rizo-Patrón de Lerner \\ Pontificia Universidad Católica del Perú \\ rosemary.rizopatron@pucp.edu.pe
}

\begin{abstract}
The role of philosophy and the human sciences in forging an "ideal of humanity" concerns not only the tensions that they traditionally have had with worldly powers. It mostly deals with their primal role as guides of an ideal of humanity and spiritual values in times of crisis. Kant defended the central role of the "Faculty of Philosophy"'s rational ideals by the end of the 18th century, as opposed to Theology, Jurisprudence and Medicine. Fichte's reflection when the German nation was fighting for its survival after its defeat by the Napoleonic armies at the beginning of the 19th century, gives a decisive impulse to the values brandished by German Idealism. A century later, facing the same German nation newly defeated at World War I, and without any answers to its affliction either in exact sciences nor in its culture determined by technology, Husserl finds in "Fichte's Ideal of Humanity" the answer to that which can give it its lasting satisfaction: the teleological production of a human world, in which a world moral order may arise, as humanity's sole goal, foundation, and absolute value. Today we find ourselves in another moment of danger: not only that of a naturalistic positivism displacing a humanistic education. The greatest of all dangers is currently the alliance of this naturalism with the Golden calf installed in the globalized world of today, under the empire of the bureaucratic and corporative standardization at the service of the frenzied production of money.
\end{abstract}

Keywords: Kant. Fichte. Husserl. German Idealism. Humanities. Rational values.

1 Este texto se presentó originalmente en el Congreso Internacional en Conmemoración del Centenario de la Pontificia Universidad Católica del Perú: El Conflicto de las Facultades. Sobre la universidad y el sentido de las humanidades, en septiembre de 2017. 
No hay que esperar a la aparición de las universidades europeas en el siglo XIII, o al giro radical que parece introducirse en el rumbo de la historia europea desde la llamada Ilustración en la Edad Moderna, para constatar la difícil relación que el filósofo siempre ha mantenido - como señala Merleau Ponty- "con los dioses de la Ciudad, es decir, con los otros hombres y con lo absoluto fijado, cuya imagen ellos le tienden" (Merleau-Ponty 2006: 9). En El elogio de la filosofía, de 1953, Merleau-Ponty señala -refiriéndose a la vida y la muerte de Sócratesque no sería tanto un problema "si el filósofo fuese un rebelde"; pues, "la rebelión" en tanto tal "no desagrada". Por el contrario, Sócrates ofrece sacrificios a los dioses, señala que su religión es verdadera, y conmina a los ciudadanos a "obedecer a la Ciudad". Es, además, el primero en dar el ejemplo: "Atenienses -dice en la Apología- yo creo como ninguno de los que me acusan." Lo condenan a muerte, entonces, no tanto por lo que hace, sino por cómo lo hace, y por qué lo hace (ib. 25). A diferencia de los humanismos ideológico-políticos, inspirados en el Mito de Prometeo, en abierta rebelión contra los dioses y las teologías, a los cuales recusan con violencia, el filósofo no propone certezas alternativas ni es capaz de asegurar sociedades futuras pluscuamperfectas habitadas por algún homo absconditus inédito, totalmente realizado. Propone otro discurso $-\mathrm{y}$ otro humanismo, que incomoda $y$ decepciona. No ofrece certezas ni verdades establecidas; se rehúsa a habitar en ellas, rehaciendo continuamente sus pasos: "Los filósofos más resueltos quieren siempre los contrarios: realizar, pero destruyendo, suprimir, pero conservando. Siempre tienen una segunda intención. El filósofo dedica al hombre serio -a la acción, a la religión, a las pasiones- una atención quizá más aguda que nadie. Pero allí justamente se advierte que nada de eso le atañe" (ib. 38). En suma, el filósofo, advierte Merleau-Ponty, no es un hombre serio. "El hombre serio, si existe, es el hombre que dice sí a una sola cosa", por ello - añade- "los maniqueos que chocan en la acción se entienden mejor entre ellos que con el filósofo: hay entre ellos complicidad, cada uno es la razón de ser del otro. El filósofo es un extraño en este enredo fraternal. Aunque jamás haya traicionado, se siente, en su manera de ser fiel, que podría traicionar; no toma parte como los otros, falta a su asentimiento, algo de macizo y de carnal [...] no es completamente un ser real" (ib. 39). 
Diferentes formas asumen los poderes establecidos a lo largo de la historia. Contra todas ellas, ha chocado una y otra vez el pensamiento racional, voluntario y libre. Cuando Kant publica su Religión en los límites de la razón en 1794, un edicto real de Federico Guillermo II de Prusia elaborado en 1788 por un eclesiástico del Departamento de Culto, censura la obra. El soberano le hace llegar al autor una misiva señalando que ha "abusado de su filosofía" "para desfigurar y envilecer diversos dogmas capitales y fundamentales de la Sagrada Escritura y del Cristianismo", conminándolo a no volver a "cometer errores semejantes" (Kant 1963, 9-11). En su defensa, Kant responde al soberano que, en su calidad de "maestro de la juventud" y "maestro del pueblo", su libro no contiene pronunciamiento alguno referido a las Sagradas Escrituras, la Biblia ni al Cristianismo en particular, y que "sólo contiene un juicio sobre la religión natural", declarándose "el más fiel de los súbditos". En 1798, Kant publica El conflicto de las facultades en el que, lamentándose acerca del "impulso permanente hacia una fe que se aleja cada vez más de la razón" (ib. 16), intenta explicar no sólo el papel directo que cumple la Facultad de filosofía - considerada "inferior"- "sirviendo" a las facultades dizque "superiores" en el contexto de la Universidad, sino también su papel indirecto como "guía" del poder soberano en el gobierno de su pueblo con la "antorcha" de la razón.

Si a las facultades de Teología, Derecho y Medicina se las considera "superiores" en el sistema universitario alemán, aclara Kant, es porque mediante la enseñanza pública de las síntesis teóricas que ellas ofrecen y sus estatutos legales - el Estado y el soberano pueden ejercer la autoridad del poder sobre su pueblo y exigir obediencia, ofreciendo a sus ciudadanos a cambio garantías de acceso al bien eterno, al bien civil y al bien corporal -esto último en cuanto a la vida y la salud (ib. 25-28). Ninguna de dichas facultades extrae sus conocimientos de la demostración racional de sus interpretaciones y reglamentos, ni requiere hacerlo. En cambio, la Facultad de filosofía es considerada "inferior", pues no sirve directamente al soberano para coadyuvar el orden social y el poder político. Su fin es meramente el de ejercer el poder de juzgar conforme a la razón, demostrar de modo autónomo y libre las verdades que alcanza, protegerlas contra la injerencia y el dominio de fuerzas exteriores. Asimismo, debe abstenerse de lesionar al poder civil comunicando directamente al pueblo sus reservas críticas respecto de la falta de sustento racional de las legislaciones civiles y eclesiásticas. Cabe añadir que la Facultad de Filosofía tampoco es una 
mera facultad humanística tal como se entiende en la actualidad, sino que "abarca todas las ramas del saber humano", inclusive las de las "facultades superiores". Vale decir, abarca las ciencias históricas propiamente humanísticas entendidas en su conexión con las ciencias naturales empíricas, y las ciencias racionales puras como la matemática pura y las metafísicas de la naturaleza y las costumbres (ib. 36). Su propio trabajo filosófico reflexivo conduce a Kant a descubrir que éste tiene como tema principal ser una "ciencia del hombre", "tal como es y como debe ser, tanto según sus disposiciones naturales, como también según la condición de su moralidad y libertad" (ib. 99). Fundamentalmente, Kant asigna al ser humano en el mundo una existencia eminentemente activa, en tanto "originariamente creador de sus representaciones y conceptos", y "autor de todas sus acciones." (ib. 100) Gracias a su sensibilidad y entendimiento determina lo que es, y gracias a su razón y voluntad - que tienden a lo suprasensible- lo que debe ser. Habita, pues, entre dos mundos: el sensible y el inteligible. Pero es su razón práctica, autónoma y libre, lo que lo diferencia del animal. La actividad creadora del entendimiento en relación a sus objetos de conocimiento está atada a la afección de la sensibilidad, y por ello, en cierto sentido - nos dice Kantdepende del cuerpo y la acción cerebral, como enseña la fisiología. No así la facultad práctica de la voluntad libre y la razón, fuentes de la ley moral, que nos eleva por encima de la naturaleza.

Johann-Gottlieb Fichte (1762-1814), después de su contacto con el Tratado teológico-político y la Ética de Spinoza, descubre maravillado la filosofía práctica de Kant como la primera que, a sus ojos, logra conciliar un sistema racional con la libertad humana (Julia 1964, 3). Cuando el edicto real censura La religión en los límites de la simple razón de Kant, Fichte se vuelve revolucionario, se rebela contra el Estado y decide luchar en adelante por la libertad de pensamiento. Su itinerario intelectual desde entonces parece desarrollarse en etapas discontinuas, explotando el principio activo de la filosofía kantiana desde su filosofía idealista del yo (entre 1794 y 1799), pasando por una filosofía del ser o realismo absoluto (entre 1800 y 1802), y concluyendo con una filosofía del absoluto que concilia las dos primeras etapas (entre 1804 y su muerte en 1814).

Desde un inicio, sus Principios fundamentales de la teoría de la ciencia (Grundlage der gesamten Wissenschaftslehre) de 1794 -obra que expone los derechos de una nueva metafísica - pretende dar un fundamento unitario a la 
filosofía desde una "teoría exhaustiva del hombre". Su objeto es conocer el espíritu humano como fuente de "toda ciencia y de toda acción". Fichte es de la opinión que Kant no habría logrado determinar con su Crítica del juicio el fundamento común entre el espíritu y la naturaleza, cosa que él se propone con su concepto de acción originaria (Tathandlung) que emana del "yo trascendental", como principio ideal del conocimiento y principio real de la acción. El auto-desdoblamiento del yo en una actividad tética creadora (la espontaneidad del pensamiento), por un lado, y en lo dado (la pasividad de la intuición), por el otro, describe la profunda interpenetración de ambos elementos en el conocimiento del universo. Sus textos iniciales suscitan rechazo, y se le acusa de ateísmo y de complotar contra el Estado. Su "filosofía del ser" expuesta de modo popular en su Die Bestimmung des Menschen de 1800 (Fichte 1974) y de modo sistemático en una reformulación de su Wissenschaftslehre en 1801, reintenta conciliar las exigencias de la razón y del corazón: pensamos objetivamente el determinismo (que está al alcance de nuestro poder) y sentimos subjetivamente la libertad (que se halla al alcance de nuestro querer). Descubre así que más profundo que el "yo" y su "idealismo absoluto" se halla el "ser absoluto del saber", en el marco de un "realismo absoluto". Así, una fenomenología de la conciencia perceptiva y la conciencia moral en su obra de 1801 relata la historia de las determinaciones del ser absoluto.

Luego, en 1804, reformulando su Teoría de la ciencia, se aboca a conciliar su filosofía de la conciencia (la del yo absoluto y libre) y su filosofía del ser absoluto. Considera en ese momento que su teoría de la acción (la ciencia filosófica real) - siendo inacabada - no logra todavía resolver aquel problema. A pesar de ello, la considera un avance respecto de la de Kant: pues en su teoría el fin de la moral no es el individuo, sino la humanidad; y su noción fundamental no es la ley formal sino el progreso asegurado por las leyes educativas concretas, que apuntan a una mejora de la constitución civil de los Estados y a una confederación de Estados, fundada ésta en derechos internacionales capaces de preservar la paz y la realización de una humanidad como comunidad real. En relación a esto último, cabe añadir que más tarde Fichte también precisa, en su Teoría del Estado de 1813, las condiciones económicas de los Estados en contra de dos extremos nocivos: el liberalismo económico (pues suscita la guerra de individuos y naciones) y el mercantilismo (pues suscita monopolios en detrimento de los consumidores). Aboga, en su lugar, por un socialismo económico estatal, por encima 
de todo interés particular, que él piensa será capaz de orientar la producción económica en el sentido de las necesidades e intereses de productores, comerciantes y consumidores. En suma, a lo largo de las tres etapas que recorre toda su obra, hay una profundización y articulación progresiva de los dos elementos-eje que la integran: el yo absoluto y el ser absoluto conducen -en una unidad dialéctica- a la metafísica del Verbo absoluto de la tercera y última etapa, influido por el esquema de Gotthold Ephraim Lessing en La educación del género humano (Die Erziehung des Menschengeschlechts, 1780).

Según Fichte el hombre es, en efecto, un sujeto pero comprometido en el mundo. La armonía última entre el sujeto y el ser real la pre-establece la divina providencia. Así, su concepto de "absoluto", en profundización creciente, va paulatinamente apareciendo como ser, sujeto, acción, providencia y ciencia, temas que - poco más de un siglo después, en 1917- retomará Husserl en sus tres lecciones o conferencias sobre el "Ideal de la Humanidad de Fichte" (Hua XXV, 267-293). Si según Husserl el principio que subyace a todos los escritos de Fichte es fenomenológico -entendido este principio como dialéctica o génesis vivida que determina todas nuestras cosmovisiones y nuestra libertad, incluyendo nuestra vivencia del saber absoluto-, es porque para él (a diferencia de Hegel) el elemento ético, en tanto fenomenológico o vivido, es irreductible a todo saber conceptual. El fundamento y fin de su metafísica es pues en última instancia moral, expresado en el anhelo y adquisición de una "beatitud" que, allende la vida de los hombres, consiste en participar de la vida divina. La finalidad del hombre - del humanismo- que está en el corazón de la antropología de Fichte, es pues realizar la Aufhebung de toda ontología dualista (en el sentido de suprimir, superando y conservando): vale decir, realizar la superación de todo hiato entre el yo y el no-yo, la razón y la materia, la libertad y la naturaleza.

Husserl empieza a leer a Fichte intensamente, dedicando seminarios y cursos sobre todo a La finalidad del hombre, tanto en 1903, 1915 como en 1918. Sus lecciones de ética desde 1919, 1920-1921 y 1924 también revelan su fuerte influencia. Precisamente al final de sus lecciones de ética de 1924, en una nota a pie de página (Hua XXXVII, 255)², se lamenta de no haber podido mencionar en el curso el parentesco entre su fundamentación fenomenológica científica de

\footnotetext{
${ }^{2}$ Indicación que agradezco a mi colega Mariana Chu, una de las traductoras al castellano de Hua 37, lecciones de ética del período genético de Husserl (entre 1920-1924), edición que aparecerá en Trotta. 
la ética y la ética de Fichte. Su deferencia por este autor del Idealismo Alemán va en aumento, basada sobre todo en su lectura de la obra popular de 1800 ( $L a$ finalidad del hombre), y no tanto de la Teoría de la ciencia, especialmente en su versión de 1804, obra que en opinión de Husserl contiene demasiadas "acrobacias" argumentativas y violencias a la lógica que le parecen casi insoportables (Hua XXV, 269). Admira, sin embargo, la ética y pasión humanista de Fichte, la cual reconoce estar continuamente referida a su fundamentación teorética. Concuerda con Fichte cuando éste sostiene que "uno puede hacer otras cosas por razones secundarias o egoístas; pero el filósofo sólo puede serlo como una personalidad ética, si no, no es nada" (Hua XXV, 309; cf. Hart, 1995, 135-163).

Las tres lecciones sobre "El ideal de la humanidad en Fichte" ("Fichtes Menschheitsideal") las dictó Husserl primero en noviembre de 1917 a soldados que regresaban del frente de la guerra. Las repitió dos veces en 1918 para los estudiantes y la facultad de la Universidad de Friburgo (cf. ib. XXVIII-XXXIII). El contexto son los estragos de la guerra y el desánimo de la derrota. Se pregunta si se han agotado en el pueblo alemán los valores que dieron impulso al idealismo alemán y a la vida espiritual del hombre moderno, aplastados por el avance de las ciencias exactas y su cultura determinada por la técnica; se pregunta asimismo si la filosofía ya no tiene nada que decir. En épocas de Fichte, a inicios del siglo 18, Alemania luchaba por su existencia luego de la derrota prusiana en Jena por los ejércitos napoleónicos. En 1917, un siglo después, cunde el imperio de la muerte que le ha arrebatado a Husserl su hijo menor el año anterior en el frente de Verdún. Considera por ello que el idealismo alemán ha reconquistado su derecho originario y sagrado a ser revalorado. La orientación fundamentalmente "práctica" de Fichte -como reformador ético-religioso, educador de la humanidad, profeta y visionario- invita a reconsiderar las premoniciones de su obra (ib. 270). Entretanto, la situación ha cambiado algo, siendo sin embargo una consecuencia de problemas anteriores que se arrastran. Luego de la "caída" idealismo alemán con la muerte de Hegel, triunfa el "naturalismo" positivista desde Comte - profundizando (como señalará Husserl más tarde) las consecuencias que el fisicalismo moderno y el dualismo cartesiano han infligido sobre la naciente psicología y el estudio de la subjetividad. Desde el naturalismo y cientificismo dominante, observa Husserl, se renuevan no sólo críticas a la metafísica sino al discurso filosófico mismo. Estas críticas olvidan que el desarrollo y creación de las herramientas epistemológicas y técnicas que han posibilitado la 
constitución y el triunfo de ciencias rigurosas en el dominio de la naturaleza en la modernidad, es fruto de siglos de ingentes esfuerzos que provienen de espíritus tanto filosóficos como científicos - dirigidos por intuiciones geniales. Pero sobre todo, destaca Husserl que las premoniciones filosóficas del pasado han ofrecido "tomas de posición decisivas para la dignidad de la humanidad auténtica" con el rigor de ideales teoréticos (ib. 270).

Son varios textos de Fichte que lo inspiran ${ }^{3}$, y sus conferencias se inician con una exposición de las iniciales tesis fichteanas que lo caracterizan como un kantiano (ib. 274). Pero admira en Fichte su audacia de interpretar el mundo de modo totalmente distinto al de las ciencias naturales, borrando asimismo la cosa en sí kantiana y toda afección. La orientación práctica de su pensamiento lo conduce a un concepto de subjetividad hacedora. "El sujeto es de parte a parte hacedor. El sustrato de su acción, el objeto de su actividad, lo que tiene siempre frente a sí, es algo ya trabajado por él. Sujeto y hacedor coinciden [...] no hay nada antes de la acción" (ib. 275). En el comienzo no hay un hecho (Tatsache) sino una acción (Tathandlung) desplegada en una historia, en un proceso productivo de continuas tareas, en sucesión infinita. La meta de cada tarea se conecta con la meta más elevada: la meta ética (ib.). En eso consiste el "yo" o "inteligencia" fichteana que Husserl admira, que no es un mero objeto de la experiencia, sino, una potencia metafísica, capaz de desdoblarse y reconstruir el proceso teleológico de sus experiencias, gracias a las cuales se construye el sentido que atribuimos al mundo y a nosotros mismos (ib. 276). Husserl se pregunta con Fichte: ¿Adónde apunta esta teleología, y cuál es su último sentido? La respuesta es que sólo apunta hacia aquello que puede darle -como valor absoluto- una ultima satisfacción: la producción teleológica de un mundo humano, en el que mediante la acción ética de espíritus libres, pueda realizarse un orden mundial moral, único fin, fundamento y valor absoluto del mundo (ib. 277). La mera causalidad natural es incapaz de descubrir -en nuestra experiencia- esta necesidad teleológico-práctica. Esto intenta lograr el idealismo de Fichte, a quien Husserl cita: "Nada tiene valor incondicional y significado excepto la vida; el resto del pensar, poetizar, y conocer sólo tiene valor en la medida en

\footnotetext{
${ }^{3}$ Los textos que menciona como lecturas indispensables son Die Bestimmung des Menschen (1800), Die Grundzüge des gegenwärtigen Zeitalters (1806), Die Anweisung zum seligen Leben, Die Reden an die Deutsche Nation (1808), las lecciones de Erlanger Über das Wesen des Gelehrten (1805), y las cinco lecciones de Berlín sobre Die Bestimmung des Gelehrten (1811). Cf. Hua 25, 271.
} 
que de algún modo se relaciona a la vida, procede de ella e intenta regresar a ella" (Fichte 1908, 557ss, en Hua XXV, 278). La filosofía de Fichte propone un "nuevo ideal de humanidad", que requiere - en palabras de Husserl que evocan a Nietzsche- una "transvaloración de todos los valores" (Umwertung aller Werte) (Hua XXV, 279). Esta filosofía y nuevo ideal yacen en y emanan de la pura interioridad y del valor de la personalidad, como agente moral y ciudadano libre. La filosofía verdadera enseña así el camino de la salvación y el ideal genuino de la humanidad que vive moralmente, y en la cual coinciden el hombre ético y su finalidad religiosa.

Husserl termina estas conferencias sobre el "Ideal de la Humanidad en Fichte", refiriéndose a la última reformulación que éste elabora de la relación entre el ser humano y Dios en su obra de 1806, Anweisung zum seligen Leben (Hacia una vida bienaventurada) (ib. 284). En ésta, Fichte indica que Dios eterno e inmutable se auto-revela en grados infinitos y en distintas formas en la conciencia de sí de los individuos, primero de modo oscuro y en ascenso hasta la conciencia pura de sí mismo. Describe cinco estadios de auto-revelación divina en la interioridad humana, que corresponden a distintas antropologías y cosmovisiones. Se excluye al primero de los mismos, por ser puramente negativo, el de la mera sensualidad que busca la felicidad en el placer, propio de un dogmatismo hedonista. Los siguientes, en ascensión creciente, caracterizan cuatro tipos humanos ideales: 1 . El de la eticidad (Sittlichkeit) correspondiente a la moralidad kantiana y estoica de la legalidad rigurosa y sometimiento al deber, ya libre de la "afección sensible del ser", pero meramente negativa por carecer de contenido. 2. El segundo constituye una moralidad más elevada y auténtica, aquella correspondiente al amor positivo por el valor de las cosas mismas. Este tipo humano se expresa en el artista creador (ib. 288); en el auténtico inves-tigador científico; en la nobleza del tecnólogo, cuyo amor apunta a la creación de medios humanos para someter a la naturaleza; y, en el político noble que se beatifica luchando por formar un estado como ordenamiento de la comunidad ideal (ib. 289). Este tercer estadio corresponde a aquel que ama a su prójimo en la medida que este amor emana del infinito amor de Dios, y que, como miembro de un mundo ideal de los espíritus, busca realizar el reino de Dios en la tierra. Corresponde a la moralidad de la persona religiosa. Husserl cita a Fichte: "¿Quieres ver a Dios como Él es en sí mismo, cara a cara? No lo busques al otro lado de las nubes. [...] Dedícate tú mismo a Él, y lo hallarás en tu pecho" (Werke V, 184) (Hua XXV, 
292). Y, finalmente, 4. el nivel más elevado, el cuarto, es para Fichte, como señala Husserl, el ideal de la humanidad científica, que eleva la fe al conocimiento filosófico de un "ver" - aunque Husserl advierte que se trata de un mero vistazo indirecto, no realizable teoréticamente, sino que se satisface prácticamente en tareas infinitas (ib.).

En la actualidad, son nuevos becerros de oro los que amenazan la posibilidad filosófica de forjar o revivir desde las aulas universitarias un Ideal de la humanidad en el sentido más elevado del término - guiado éste por la auténtica vocación científica de la búsqueda de la verdad, de la acción práctica, y del hacer productivo noble hacia los fines supremos de la humanidad. Dicho Ideal no se forja únicamente desde las humanidades y la filosofía, sino también -en el sentido del concepto kantiano más amplio de Facultad de Filosofía - en diálogo con las ciencias puras y aplicadas. El mayor de los peligros no es solamente el positivismo naturalista rampante cuyos gérmenes se sembraron en la modernidad desde el triunfo del fisicalismo matemático en las ciencias naturales, y que terminó de invadir el espíritu de Occidente y del globo terráqueo desde el siglo XIX, y ante el cual se rebela críticamente el proyecto fenomenológico bebiendo de Kant y de Fichte. El mayor de los peligros es en la actualidad la alianza de ese naturalismo que ha ido crecientemente desplazando y excluyendo a las ciencias humanas y del espíritu del mundo académico superior y la educación secundaria, con el becerro de oro instalado en el mundo globalizado del presente, bajo el imperio de la normalización burocrática estandarizada y corporativa al servicio de la producción ilimitada del dinero. La amenaza del mundo actual, ante la cual las facultades humanísticas y filosóficas universitarias y su investigación más genuina no han de perder su papel protagónico y moral, así como levantar su voz crítica ante las tentativas crecientes de silenciarlas, es la transvaloración más peligrosa: la reducción del valor más elevado de la educación y la formación integrales - cuya finalidad es el ideal de una humanidad realizada- a la más despreciable y dispensable de las mercancías. 


\section{BiBLIOGRAFÍA}

FICHTE, J. G. (1908 ss). Werke: Auswahl in sechs Bänden: Vol. III, Leipzig: ed. Fritz Medicus.

-, (1974). Die Bestimmung des Menschen, Stuttgart: Philipp Reclam [reproducción de la $1^{\text {a }}$ edición: 1800. Berlin: Vosschichen Buchhandlung].

HART, James (1995). "Husserl and Fichte: With Special Regard to Husserl's Lectures on Fichte's Ideal of Humanity", Husserl Studies, Vol. 12: 135163.

HUSSERL, Edmund (1950 ss). Husserliana: Edmund Husserl Gesammelte Werke. La Haya / Dordrecht: Martinus Nijhoff / Kluwer Academic Publishers / Springer.

—, (1987). Hua XXV: "Fichte's Menschheitsideal", en Aufsätze und Vorträge 1911-1921, eds. Thomas Nenon / Hans Rainer Sepp, Dordrecht: Martinus Nijhoff, pp. 267-293.

-, (2004). Hua XXXVII: Einleitung in die Ethik, Vorlesungen Sommer-semester 1920-1924, ed. H. Peucker, Dordrecht: Kluwer Academic Publishers.

JULIA, Didier (1964). Fichte, sa vie, son oeuvre, avec un exposé de sa philosophie, París: Presses Universitaires de France.

KANT, Manuel (1963). El conflicto de las facultades, trad. Elsa Tabernig, Buenos Aires: Editorial Losada.

MERLEAU-PONTY, Maurice (2006). El elogio de la filosofía, seguido de El lenguaje y las voces del silencio, trad. Amalia Letellier, Buenos Aires: Ediciones Nueva Visión. 